\title{
Effect of vegetation density, height, and connectivity on the oviposition pattern of the leaf beetle Galeruca tanaceti
}

\author{
Barbara Randlkofer ${ }^{1}$, Florian Jordan ${ }^{1}$, Oliver Mitesser $^{2}$, Torsten Meiners ${ }^{1} \&$ \\ Elisabeth Obermaier ${ }^{3, *}$ \\ ${ }^{1}$ Department of Applied Zoology/ Animal Ecology, Freie Universität Berlin, Haderslebener Str. 9, \\ D-12163 Berlin, Germany, \\ ${ }^{2}$ Field Station of the University ofWürzburg, Glashüttenstr. 5, D-96181 Rauhenebrach, Germany, and \\ ${ }^{3}$ Department of Animal Ecology and Tropical Biology, Biozentrum, University of Würzburg, Am Hubland, \\ D-97074 Würzburg, Germany
}

*Correspondence: Elisabeth Obermaier, Department of Animal Ecology and Tropical Biology, University of Würzburg, Biozentrum, Am Hubland, D-97074 Würzburg, Germany. E-mail: o.maier@biozentrum.uni-wuerzburg.de

\begin{abstract}
Vegetation structure can profoundly influence patterns of abundance, distribution, and reproduction of herbivorous insects and their susceptibility to natural enemies. The three main structural traits of herbaceous vegetation are density, height, and connectivity. This study determined the herbivore response to each of these three parameters by analysing oviposition patterns in the field and studying the underlying mechanisms in laboratory bioassays. The generalist leaf beetle, Galeruca tanaceti L. (Coleoptera: Chrysomelidae), preferentially deposits its egg clutches on non-host plants such as grasses. Earlier studies revealed that oviposition within structurally complex vegetation reduces the risk of egg parasitism. Consequently, leaf beetle females should prefer patches with dense, tall, or connected vegetation for oviposition in order to increase their reproductive success. In the present study, we tested the following three hypotheses on the effect of stem density, height, and connectivity on oviposition: (1) Within habitats, the number of egg clutches in areas with high stem densities is disproportionately higher than in low-density areas. The number of egg clutches on (2) tall stems or (3) in vegetation with high connectivity is higher than expected for a random distribution. In the field, stem density and height were positively correlated with egg clutch presence. Moreover, a disproportionately high presence of egg clutches was determined in patches with high stem densities. Stem height had a positive influence on oviposition, also in a laboratory two-choice bioassay, whereas stem density and connectivity did not affect oviposition preferences in the laboratory. Therefore, stem height and, potentially, density, but not connectivity, seem to trigger oviposition site selection of the herbivore. This study made evident that certain, but not all traits of the vegetation structure can impose a strong influence on oviposition patterns of herbivorous insects. The results were finally compared with data on the movement patterns of the specialised egg parasitoid of the herbivore in comparable types of vegetation structure.
\end{abstract}

Key words: Coleoptera, Chrysomelidae, tansy leaf beetle, vegetation structure, Oomyzus galerucivorus, Hymenoptera, Eulophidae 


\section{Introduction}

Structural complexity of the vegetation is considered to be an important factor influencing the population dynamics and trophic organisation of terrestrial arthropods (Price et al., 1980; Dennis, 2004; Langellotto \& Denno, 2004). Plant structures can interfere with herbivore behaviour in a direct or indirect way. The structural complexity of habitats and the architectural traits of single plants influence, for example, the ability of herbivores to move and thus their host-finding process (Goodwin \& Fahrig, 2002; Hannunen, 2002). In particular, the height and density of the vegetation within habitats play a role here. Tall and dense vegetation in the neighbourhood of host plants may either visually mask the target plant or impair access to the target plant (Finch \& Collier, 2000; Åsman et al., 2001). Aside from visual camouflage, physical impediment caused by neighbouring plants may diminish the dispersal rate of insect herbivores (Perrin \& Phillips, 1978). Dense vegetation may slow down the speed of movement by exerting a certain spatial resistance on individuals walking on the ground (Jopp, 2006) or on individuals conducting flights at low altitude, as proposed by Coll $\&$ Bottrell (1994). The herbivore load of trees was shown to decrease as non-host density increased, consistent with the associational resistance hypothesis (Sholes, 2008). Thus, structural traits of the vegetation affect the access to resources and with it, the population dynamics of phytophagous arthropods. Vegetation structure can furthermore modify the abiotic conditions prevailing in the environment and may therefore impact colonisation dynamics by affecting the abundance and the reproductive behaviour of herbivores, which in turn can result in distinct distribution patterns of herbivores within and between different types of habitats (Bach, 1993; Raghu et al., 2004; Veldtman et al., 2007). Plant structures, however, can also indirectly affect herbivores via natural enemies. Complex plant structures may provide shelter for natural enemies of herbivores (Langellotto \& Denno, 2004; Shaw, 2006) or, in contrast, may render host search by their enemies more difficult (Tschanz et al., 2005; Obermaier et al., 2008) with important implications for the herbivorous host.

The implication of structural complexity of the vegetation for herbivorous insects and their susceptibility to natural enemies has only recently started to be investigated (Casas \& Djemai, 2002; Meiners \& Obermaier, 2004; Riihimäki et al., 2006; Obermaier et al., 2008). The relative complexity of habitats is determined largely by the number of different structural elements per volume (McCoy \& Bell, 1991), their height, and their spatial arrangement. While the importance of single components of plant architecture for terrestrial arthropods is receiving increasing attention (Andow \& Prokrym, 1990; Gingras et al., 2002; Riihimäki et al., 2006), the effect of the various structural traits of the vegetation on larger spatial scales has so far not been studied systematically. Therefore, this is, to the best of our knowledge, the first study to investigate simultaneously the influence of the three main traits of vegetation structure, density (number of plant stems per unit area), height (mean plant size), and connectivity (number of contacts between individual plants), on the oviposition site selection of a leaf beetle in the natural setup of whole vegetation patches. The classification of structural parameters was chosen with respect to previous characterizations of the architecture of single plants (Andow \& Prokrym, 1990; Gingras et al., 2002). The structural parameters were recorded in the field, and their effect on herbivore oviposition was tested separately in bioassays in the laboratory to unravel the underlying mechanisms of oviposition choice due to plant structural traits, in order to explain patterns observed in the field.

The tansy leaf beetle, Galeruca tanaceti L. (Coleoptera: Chrysomelidae), was chosen as a model organism because it lays eggs in clutches on vertical plant structures (mainly dry grass stems) in grasslands in autumn (Obermaier et al., 2006). The eggs are subject to heavy parasitism by the specialised egg parasitoid, Oomyzus galerucivorus Hedqvist (Hymenoptera: Eulophidae) (Meiners et al., 2006). Previous studies have shown that tall and complexstructured vegetation reduces the risk of parasitism and might therefore provide enemy-free space for the leaf beetle (Meiners \& Obermaier, 2004; Obermaier et al., 2006, 2008). In the 
present study, the following hypotheses on the effect of stem density, height, and connectivity on oviposition site selection of the herbivore were tested: (1a) leaf beetle females encounter grass stems used for oviposition by chance. Thus, the number of egg clutches rises directly proportionally with increasing stem density; (1b) females prefer sites with high stem densities for egg deposition (the number of egg depositions is disproportionately high in areas with high stem density compared with low stem density areas); (2) females prefer tall vegetation and the number of egg clutches on tall stems is higher than on low stems; (3) females prefer highly-connected vegetation and the number of egg clutches in vegetation with high connectivity is higher than in that with no connectivity.

\section{Materials and methods}

\section{Life-history of Galeruca tanaceti}

The polyphagous tansy leaf beetle, G. tanaceti, feeds on species of the families Asteraceae, Brassicaceae, Caryophyllaceae, Dipsacaceae, Liliaceae, Lamiaceae, Polygonaceae, and Solanaceae (Lühmann, 1939; Prevett, 1953; Obermaier \& Zwölfer, 1999) and sometimes occurs as a pest on cultural plants (e.g., Roditakis \& Roditakis, 2006). Food plants are rarely used for oviposition. Female leaf beetles oviposit well above the ground on dry vertical structures,mostly grass stems, within the herbaceous vegetation layer in autumn (Scherf, 1966; Obermaier et al., 2006). Females oviposit about once a week after being fed ad libitum in the laboratory at $22^{\circ} \mathrm{C}$ (B Randlkofer, pers. obs.). Gravid females are unable to fly and must walk up the plant structures for oviposition. Eggs are deposited in clutches and are subject to parasitism by the specialised egg parasitoid O. galerucivorus. Hibernation takes place at the egg stage. In the following spring, the beetle larvae hatch and they pupate 3 weeks later. The emerging adults enter a reproductive diapause until September (Siew, 1966; Meiners et al., 2006).

\section{Field survey}

Analysis of the vegetation structure. The field study was conducted in Northern Bavaria, Germany $\left(50^{\circ} 03^{\prime} \mathrm{N}, 10^{\circ} \mathrm{E}\right)$ at four semi-arid grassland sites ranging from 1300 to $12000 \mathrm{~m}^{2}$ that were unmown (sites Lichtlein and Sechsthal) or grazed by sheep occasionally (sites Schafhof and Hoher Landsberg). The vegetation structure of the microhabitats $(\mathrm{r}=0.1 \mathrm{~m})$ around egg clutches (oviposition plots) was compared with the vegetation structure of microhabitats without egg clutches (control plots). In order to choose the oviposition and control plots randomly, random points were generated using a geographic information system (GISArcView 3.2; ESRI, Redlands, CA, USA). A handheld GPS device (Garmin ${ }^{\circledR}$ GPS 12 Personal Navigator ${ }^{\circledR}$; Garmin International, Olathe, KS, USA) was used to locate these random points within the study site. A sample of 60 oviposition plots and 50 control plots was analysed on the sites Lichtlein and Schafhof, whereas on the site Sechsthal a sample of 32 control and 33 oviposition plots was analysed. On two study sites (Lichtlein and Sechsthal), the sample of investigated oviposition plots represented all egg clutches occurring within the sites. In the 2 nd year, we investigated 22 oviposition and 20 control plots on site Schafhof and 91 oviposition and 49 control plots on site Hoher Landsberg. Several structural parameters were recorded: percentage horizontal plant cover (at 30 and $50 \mathrm{cmin}$ height), percentage vertical plant cover, and mean and maximum vegetation height. Horizontal vegetation structure at two heightswithin a circular plot was estimated by marking the circular plot around the egg clutch or randompoint with a metal ring and estimating the percentage of vegetation within the ring $(\mathrm{r}=0.1 \mathrm{~m})$ covering a white wooden board in the background between 20 and $30 \mathrm{~cm}$ height and between 40 and $50 \mathrm{~cm}$ height (see also Obermaier et al., 2008). The number of plant stems suitable (in terms of stability and straightness) for egg deposition was also recorded. In the 2 nd year, the connectivity of the vegetation was recorded 
using the same method on sites Schafhof and Hoher Landsberg. For this, the number of contacts between stems was counted separately for different height intervals (10-20, 20-30, and $30-40 \mathrm{~cm})$.

Host plant availability. We also registered host plant density as percentage cover within the standard radius $(\mathrm{r}=0.1 \mathrm{~m})$ on all oviposition and control plots. The main host plants of the tansy leaf beetle in the Hohe Wann region were Achillea millefolium L. and Centaurea jacea L. (Randlkofer et al., 2007).

Distribution of egg clutches with regard to stem density. Next, we investigated whether egg clutches were found in different proportions in areas with high plant stem density than can be explained by chance. For this purpose, we first determined the proportion $\mathrm{P}(\mathrm{O} \mid \mathrm{D})$ of egg clutches found in high-density areas:

$$
\begin{aligned}
& \mathrm{P}(\mathrm{O} \mid \mathrm{D}) \\
& =\frac{\text { no. oviposition plots in area with high stem density }}{\text { total number of oviposition plots }}
\end{aligned}
$$

However, this value alone is not sufficient to answer the initial question. Moreover, the proportion $\mathrm{P}(\mathrm{D})$ of high density areas itself has to be considered, otherwise a high proportion of egg clutches in high densities could just result from a disproportionate presence of highdensity areas:

$$
\mathrm{P}(\mathrm{D})=\frac{\text { no. control plots in area with high stem density }}{\text { total number of control plots }}
$$

The null hypothesis predicts that a single stemin an area with a high stem density has the same probability to bear an egg clutch as a stem in a low-density area. In this case, the number of oviposition events in areas with high stem density would be proportionally higher compared with areas with few stems (the alternative hypothesis predicts a disproportional higher number of egg clutches in areas of high stem density). In order to be able to discriminate between the two hypotheses, the probability ratio $\rho$ of expressions (1) and (2) can be used:

$$
\rho=\frac{\mathrm{P}(\mathrm{O} \mid \mathrm{D})}{\mathrm{P}(\mathrm{D})}
$$

This ratio expresses the relative number of oviposition plots in high-density areas. According to Bayes' theorem, this ratio has to equal one, if egg clutches are distributed randomly within high- and low-density areas. A result larger than one indicates that more egg clutches are found in areas with high stem density than expected according to the naturally occurring distribution of high-density areas (disproportionately more oviposition sites in high-density areas). This would suggest an oviposition preference for areas with a high stem density. In order to categorise the microhabitats correctly, we set a threshold that defines the minimum number of stems necessary to call the investigated plots high-density plots. The randomlychosen control plots without egg clutches were considered to be a representative sample 
reflecting the real proportion of areas with high plant stem density within each study site. Thus, for each study site, the mean number of plant stems occurring in control plots was calculated and defined as a general threshold between high- and low-density plots. Plots containing the same or a higher number of stems than the mean were classified as being located in high-density areas. Based on this threshold, the number of oviposition and control plots located in areas with a high plant stem density was determined.

By setting the threshold for high-density patches at the mean number of plant stems per control plot for each site, the resulting margin might not represent the appropriate threshold for the leaf beetle. Therefore, several other arbitrary thresholds were set and the resulting ratios $\rho$ were calculated according to equations (1)-(3).

\section{Two-choice bioassays}

Oviposition trials. To investigate the influence of the different features of the vegetation structure on oviposition patterns, we conducted separate laboratory bioassays for each of the parameters density, height, and connectivity. The test arenas for the density assay $(27 \times 26 \mathrm{~cm})$ consisted of floral foam covered with filter paper. Each of the arenas was placed in a plastic box (16 cm high). The edges were painted with liquid Teflon ${ }^{\mathrm{TM}}$ (Dyneon, Burgkirchen, Germany) to prevent the beetles from escaping. Dried grass stems (Dactylis glomerata L.) were used for the tests. For the stem density assay, the stems were cut uniformly to a height of $30 \mathrm{~cm}$ and were arranged in two fields in natural-occurring densities (Figure 1A): field A $(26 \times 9 \mathrm{~cm})$ contained 10 stems (stem density $=0.04$ stems per $\left.\mathrm{cm}^{2}\right)$, field $\mathrm{B}(13 \times 9 \mathrm{~cm})$ contained 20 stems $\left(\right.$ stem density $=0.17$ stems per $\left.\mathrm{cm}^{2}\right)$. For the stem height and the stem connectivity assay 36 stems per arena were used (stem density = 0.04 stems per $\mathrm{cm}^{2}$ ) (Figure 1B) and stems were arranged in arenas of the same size as above, but with sods instead of the floral foam as a floor to guarantee a more natural setting and to keep the humidity at a constant level. In the stem height assay, half of the stems had a height of $15 \mathrm{~cm}$ and the other half of $45 \mathrm{~cm}$. They were arranged in an alternating manner. In the stem connectivity assay all stems had a uniform height of $45 \mathrm{~cm}$. Three rows of stems were left without connections, in the other three rows, the stems were connected with bast fibres bound in between them at three different heights $(8,23$, and $38 \mathrm{~cm})$.
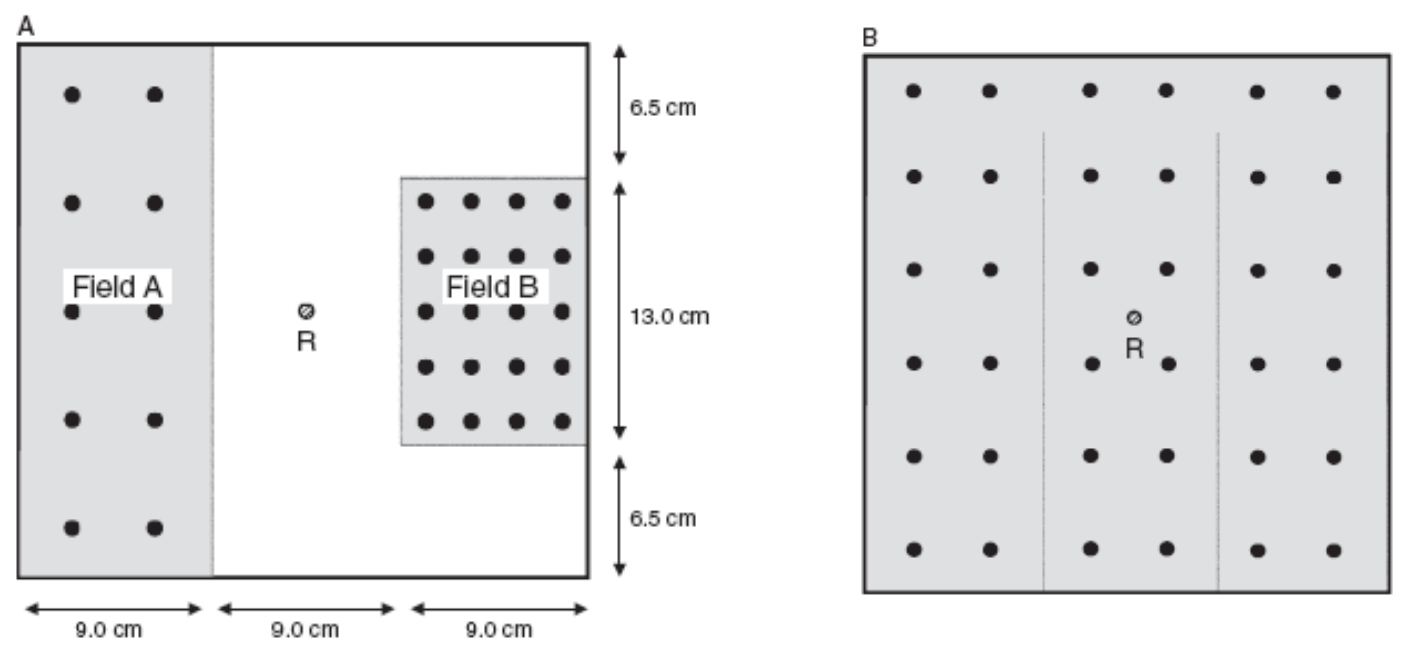

Figure 1 Schematic drawing of the two-choice bioassay arenas. (A) Stem density set-up. (B) Stem height and stem connectivity set-up. Grey areas were supplied with different numbers of grass stems according to the drawing. $\mathrm{R}=$ release point of the beetle individuals. 
Eggs of $G$. tanaceti were collected in the environs of Berlin $\left(52^{\circ} 61^{\prime} \mathrm{N}, 13^{\circ} 01^{\prime} \mathrm{E}\right)$ and Würzburg $\left(50^{\circ} 03^{\prime} \mathrm{N}, 10^{\circ} 51^{\prime} \mathrm{E}\right)$ (Germany). The egg masses were transferred to a climate chamber $\left(25^{\circ} \mathrm{C}, 60 \%\right.$ r.h., L18:D6, and 1000 lux $)$ and kept there from emergence until pupation. Larvae and adult beetles were fed with Chinese cabbage [Brassica pekinensis (Lour.) Rupr. (Brassicaceae)]. Adult beetles were kept at $15^{\circ} \mathrm{C}$ from 07:00 to 19:00 hours and at $8^{\circ} \mathrm{C}$ from 19:00 to $07: 00$ hours, 70\% r.h., L12:D12, and 800 lux to break diapause and to induce egg production.

One (stem height and connectivity assay) or five (stem density assay) gravid female leaf beetles were released in the centre of the arena for each trial and allowed to oviposit within the arena for three consecutive days. Pieces (up to $300 \mathrm{~cm}^{2}$ ) of Chinese cabbage were distributed equally over the floor of the arena to provide the beetles with food. After a female had oviposited during the course of a trial, we replaced it with a naive individual and the stem with the egg clutch was also replaced. The density assays were controlled every 15-30 min during normal working hours (09:00-19:00 hours). During the night, beetle females were removed from the arenas. Ovipositing females were observed either directly or otherwise they could be recognised by a flatter abdomen after oviposition of 50-70 eggs.

We used eight arenas for the density treatment and 10 arenas for the height and the connectivity treatment. Each of the arenas was used 2-3 times. Because the whole set of stems was replaced after each trial, these arenas were treated as new arenas. In the stem height and the stem connectivity assay, beetles were tested individually per trial. In the stem density assay, each egg deposition, which occurred during one trial, was counted individually as beetles seem not to influence each other, and stems with egg clutches were replaced at once. In only six of 20 trials of the stem density assay were more than one egg clutch deposited.

Four different outcomes could be expected for the stem density assay. (1) If the female beetles respond to plant stem density (stems per unit area), the number of egg clutches should rise directly proportionally to stem density (null hypothesis $\mathrm{A}$ in accordance with the field survey, stem density field A: stem density field $B=1: 4$ ), (Figure 1). (2) A disproportionately high number of egg clutches deposited in areas with high stem density (indicated by a 1:4+ ratio of egg clutches) would imply a preference due to an active choice of high-density areas (alternative hypothesis B in accordance with the field survey). (3) The absolute number of stems, not related to any reference value such as area, could control the egg deposition behaviour. If the number of stems alone is responsible for a given distribution of egg clutches, the expected ratio for the two-choice test is 1:2 (absolute number of stems field A: absolute number of stems field B). (4) The beetles' behaviour could be independent of any vegetational parameter and area size alone might be responsible for a given distribution of egg clutches. In this case the expected oviposition ratio would be 2:1 (size field A: size field B).

In the stem height assay and the connectivity assay, a 1:1 ratio was used as null model for the distribution of the egg clutches on short and tall stems and on connected and unconnected stems in the arena assay. Short and tall (or connected and unconnected) stems were arranged in a 1:1 ratio in the arena. It was expected that a female did not know which type of stem it was encountering when it started to climb up. Beetles did not constantly walk on the stems; there were long periods of rest, especially on the tips of the stems (E Obermaier, pers. obs.). If stems are encountered randomly, each stem should have the same probability of having an egg clutch deposited on it, and oviposition in a 1:1 ratio on short and tall (or connected and unconnected) stems should be most probable.

Behavioural observations. In addition to the oviposition trials, we also made standardised observations on the movement behaviour of the individual beetles in the height and the connectivity assays. Female beetles were observed singly and each female was used only once. Their behaviour (walking and resting) and their position (floor, stems, and arena wall) inside the arena were recorded for $10 \mathrm{~min}$. Every stem contact was registered. The 
observations were recorded using the Noldus Observer programme 3.0 (Noldus Information Technology, Wageningen, The Netherlands).

\section{Statistical analysis}

Single parameter logistic regression models were used to predict the probability of egg deposition by $G$. tanaceti depending on vegetation structure parameters (Hosmer \& Lemeshow, 1989). Correlating parameters $(r>0.7)$ with significant influence on egg deposition were either selected or summarised with principal component analysis (PCA) in a way that a comparable set of variables for each vegetation structure type and each site was available for logistic regression analysis. The goodness-of-fit of the habitat models was determined by considering the coefficient of determination $\mathrm{R}^{2}$ after Nagelkerke (1991). In order to measure the classification accuracy of the models irrespective of a particular threshold, the Receiver Operating Characteristic curve (ROC-curve) (Hanley \& McNeil, 1982, 1983) and the resulting Area Under Curve (AUC-value) were used. The AUC-value provides a measure of the diagnostic accuracy of the model (Zweig \& Campbell, 1993) and varies from 0.5 (determination by chance: null-model) to 1.0 (perfect classification) (Zweig \& Campbell, 1993; Bonn \& Schröder, 2001; see also Meiners \& Obermaier, 2004). The comparison whether the calculated probability ratios $\rho$ differ significantly from a random distribution $(\rho=1)$ was carried out with the Fisher exact test. For the bioassay data, the $\chi^{2}$ goodness-of-fit test (Statistica 1999; Stat Soft, Tulsa, OK, USA) was used to compare expected ratios with observed values and the Wilcoxon test to compare movement patterns of individual beetles. Correlations between single traits of the vegetation structure and host plant cover were performed with the Spearman rank correlation. All analyses, unless otherwise mentioned, were performed in SPSS 13.0 and 16.0 for Windows (SPSS, Chicago, IL, USA).

\section{Results}

\section{Analysis of vegetation structure in the field}

All vegetation structure parameters investigated, except connectivity, showed a significant influence on egg clutch occurrence. The strength of their impact was not consistent for all study sites (Table 1). Two out of eight recorded parameters best explained the choice of oviposition site by $G$. tanaceti for three investigated sites. These were the variables stem density and maximum vegetation height (Table 2), which both influenced the egg clutch occurrence significantly positively also when a Bonferroni correction was applied $\left(\alpha^{6}=\alpha / 2=0.025\right)$. The maximum vegetation height was on average $20 \mathrm{~cm}$ higher for microhabitats containing egg clutches compared withmicrohabitats without egg clutches. Similarly, the mean stem density in oviposition plots exceeded the mean stem density of control plots on average by 5-7 stems per plot. When both parameters were combined to a single variable through principal component analysis, the resulting models for the investigated sites showed even higher statistical validity for two study sites (Table 3). Measures of the connectivity of the vegetation were combined to a single variable by PCA as well. This factor, however, did not explain egg clutch occurrence for either of the two sites at which it was recorded. 
Table 1 The eight variables of the vegetation structure that were recorded on the study sites

\begin{tabular}{lcccc}
\hline Variable & Lichtlein & Schafhof & Sechsthal & $\begin{array}{c}\text { Hoher } \\
\text { Landsberg }\end{array}$ \\
\hline Vertical cover herbaceous layer (\%) & n.s. & + & n.s. & $-{ }^{1}$ \\
Vertical cover grass $(\%)$ & n.s. & n.s. & - & -1 \\
Horizontal cover at $30 \mathrm{~cm}(\%)$ & n.s. & + & n.s. & $-{ }^{1}$ \\
Horizontal cover at $50 \mathrm{~cm}(\%)$ & + & + & n.s. & $-{ }^{1}$ \\
Mean vegetation height $(\mathrm{cm})$ & + & + & n.s. & $-{ }^{1}$ \\
Maximum vegetation height $(\mathrm{cm})$ & + & + & + & $-{ }^{1}$ \\
Stem density (no. of stems per plot) & + & + & + & -1 \\
Connectivity of the vegetation & -1 & n.s. & -1 & n.s. \\
$(10-20 ; 20-30 ; 30-40 \mathrm{~cm})$ & & & & \\
\hline
\end{tabular}

Table 2 Model characteristics for significant univariate logistic regression models on the probability of the occurrence of Galeruca tanaceti with regard to the vegetation parameters (a) maximum vegetation height and (b) stem density for the investigated study sites.

\begin{tabular}{|c|c|c|c|c|c|c|c|c|c|}
\hline Site & $\begin{array}{l}\mathrm{n} \\
\text { oviposition }\end{array}$ & $\begin{array}{l}\mathrm{n} \\
\text { control }\end{array}$ & $\begin{array}{l}\text { Mean } \pm \text { SE } \\
\text { oviposition }\end{array}$ & $\begin{array}{l}\text { Mean } \pm \mathrm{SE} \\
\text { control }\end{array}$ & $\mathrm{R}^{2}$ Nagelkerke & $\mathrm{p}_{\text {model }}$ & Coefficient $\pm \mathrm{SE}$ & $\mathrm{AUC} \pm \mathrm{SE}$ & $\mathrm{p}_{\mathrm{ROC}}$ \\
\hline
\end{tabular}

(a) Maximum vegetation height $(\mathrm{cm})$

$\begin{array}{llllllllll}\text { Lichtlein } & 61 & 51 & 82.3 \pm 2.2 & 61.8 \pm 3.2 & 0.279 & <0.001 & 0.052 \pm 0.012 & 0.748 \pm 0.047 & <0.001 \\ \text { Schafhof } & 60 & 50 & 44.9 \pm 1.8 & 29.0 \pm 1.7 & 0.379 & <0.001 & 0.102 \pm 0.021 & 0.812 \pm 0.041 & <0.001 \\ \text { Sechsthal } & 32 & 33 & 86.9 \pm 3.7 & 62.2 \pm 5.4 & 0.241 & <0.001 & 0.035 \pm 0.011 & 0.732 \pm 0.063 & 0.001\end{array}$

(b) Stem density (number of stems per plot)

\begin{tabular}{llllllrlrr} 
Lichtlein & 61 & 51 & $15.6 \pm 1.5$ & $9.6 \pm 1.5$ & 0.093 & 0.005 & $0.051 \pm 0.020$ & $0.690 \pm 0.051$ & 0.001 \\
Schafhof & 60 & 50 & $13.7 \pm 1.1$ & $6.8 \pm 0.8$ & 0.294 & $<0.001$ & $0.186 \pm 0.044$ & $0.796 \pm 0.043$ & $<0.001$ \\
Sechsthal & 32 & 33 & $11.8 \pm 1.5$ & $6.9 \pm 0.8$ & 0.170 & 0.003 & $0.128 \pm 0.052$ & $0.684 \pm 0.066$ & 0.011 \\
\hline
\end{tabular}


Table 3 Model characteristics for significant univariate logistic regression models with the combined factors stem density and maximum vegetation height (summarised with principal component analysis) for the investigated study sites.

\begin{tabular}{llllll}
\hline Site & $\mathrm{R}^{2}$ Nagelkerke & $\mathrm{P}_{\text {model }}$ & Coefficient $\pm \mathrm{SE}$ & $\mathrm{AUC} \pm \mathrm{SE}$ & $\mathrm{P}_{\mathrm{ROC}}$ \\
\hline Lichtlein & 0.197 & $<0.001$ & $0.800 \pm 0.214$ & $0.726 \pm 0.049$ & $<0.001$ \\
Sechsthal & 0.305 & $<0.001$ & $1.311 \pm 0.389$ & $0.773 \pm 0.058$ & $<0.001$ \\
Schafhof & 0.427 & $<0.001$ & $2.455 \pm 0.497$ & $0.837 \pm 0.038$ & $<0.001$ \\
\hline
\end{tabular}

\section{Relation of vegetation structure and host plant availability}

To investigate a possible relationship between vegetation structure and host plant availability, the various structural traits were correlated with host plant cover (Table 4). There was a significant negative correlation between mean vegetation height and host plant cover (A. millefolium and C. jacea) in microhabitats when data of all three field sites were combined $(\mathrm{r}=-0.152, \mathrm{P}=0.010 ; \mathrm{n}=287)$. Vegetation density (stem number) correlated positively with host plant cover $(\mathrm{r}=0.168, \mathrm{P}=0.004 ; \mathrm{n}=287)$. Connectivity was investigated in a 2 nd year, but was not correlated with host plant cover on either site (Hoher Landsberg: $r=-0.015$, $\mathrm{P}=0.859 ; \mathrm{n}=149$ ) and (Schafhof: $\mathrm{r}=-0.128, \mathrm{P}=0.407 ; \mathrm{n}=44$ ). Stem density was also not significantly correlated with host plant cover in the 2nd year (Hoher Landsberg: $r=0.123$, $\mathrm{P}=0.133 ; \mathrm{n}=151$; Schafhof: $\mathrm{r}=-0.036, \mathrm{P}=0.815 ; \mathrm{n}=44$ ). Data on host plant cover on the three field sites in the 1st year of the study have been analysed earlier in another context in Randlkofer et al. (2007).

Table 4 Spearman rank correlations between host plant cover (Achillea millefolium and Centaurea jacea combined) and the various features of the vegetation structure: density, connectivity, and height.

\begin{tabular}{|c|c|c|c|c|}
\hline & Stem density & Connectivity & Mean height & Max height \\
\hline \multicolumn{5}{|c|}{ Year 1 (Sites Lichtlein, Schafhof, Sechsthal combined) } \\
\hline Host plant cover & $\begin{array}{l}\mathrm{r}=0.168 * * \\
\mathrm{P}=0.004 \\
\mathrm{n}=287\end{array}$ & $\begin{array}{l}- \\
- \\
-\end{array}$ & $\begin{array}{l}\mathrm{r}=-0.152^{*} \\
\mathrm{P}=0.010 \\
\mathrm{n}=287\end{array}$ & $\begin{array}{l}\mathrm{r}=-0.046 \\
\mathrm{P}=0.433 \\
\mathrm{n}=287\end{array}$ \\
\hline \multicolumn{5}{|c|}{ Year 2 (Site Hoher Landsberg) } \\
\hline Host plant cover & $\begin{array}{l}\mathrm{r}=0.123 \\
\mathrm{P}=0.133 \\
\mathrm{n}=151\end{array}$ & $\begin{array}{l}r=-0.015 \\
P=0.859 \\
n=149\end{array}$ & $\begin{array}{l}\mathrm{r}=0.048 \\
\mathrm{P}=0.562 \\
\mathrm{n}=151\end{array}$ & $\begin{array}{l}\mathrm{r}=-0.282 * * \\
\mathrm{P}=0.001 \\
\mathrm{n}=151\end{array}$ \\
\hline \multicolumn{5}{|c|}{ Year 2 (Site Schafhof) } \\
\hline Host plant cover & $\begin{array}{l}\mathrm{r}=-0.036 \\
\mathrm{P}=0.815 \\
\mathrm{n}=44\end{array}$ & $\begin{array}{l}r=-0.128 \\
P=0.407 \\
n=44\end{array}$ & $\begin{array}{l}\mathrm{r}=-0.147 \\
\mathrm{P}=0.341 \\
\mathrm{n}=44\end{array}$ & $\begin{array}{l}\mathrm{r}=-0.116 \\
\mathrm{P}=0.452 \\
\mathrm{n}=44\end{array}$ \\
\hline
\end{tabular}

Data on host plant cover, year 1, are taken from Randlkofer et al. (2007).

Bonferroni correction: $\alpha{ }^{`}=\alpha / 3=0.016$ (year 1); $\alpha=\alpha / 4=0.013$ (year 2).

* $\mathrm{P}<0.05$; * $\mathrm{P}<0.01$. 


\section{Distribution of egg clutches with regard to stem density}

In the field, the probability of oviposition increased with increasing stem density (Table 2). Based on this finding, we wanted to test whether this increase was directly proportional to the increase in the number of stems and can therefore be simply explained by chance, as suggested by the null-hypothesis, or whether there were disproportionately more egg clutches in areas with high stem density. In order to separate low from high stem density plots, the mean number of stems per control plot was used to define site-specific thresholds (Table 5). We set the threshold at seven stems per microhabitat for control plots of the sites Schafhof and Sechsthal, and 10 stems for the site Lichtlein. The resulting probability ratio $\rho$ significantly exceeded a value of 1.0 at Schafhof with $\rho=2.06$ (95\% CI range: $3.27-26.06$, odds ratio $=8.77, \mathrm{P}<0.001)$ and at Lichtlein with $\rho=1.63$ (95\% CI range: $1.07-5.72$, odds ratio $=2.45, \mathrm{P}=0.023)$, at Sechsthal a strong tendency was detected with $\rho=1.48(95 \% \mathrm{CI}$ range: $0.87-8.71$, odds ratio $=2.67, \mathrm{P}=0.077$ ). Thus, our analysis showed that egg clutches were deposited in areas with high stem density in higher proportions than compared with the overall occurrence of high-density areas on the study sites. This result strongly supports the alternative hypothesis and indicates that the leaf beetle females seem to deliberately choose microhabitats with a high stem density for oviposition. As it is not known, what is the perceptual threshold for high stem density of the beetle, arbitrary thresholds were assumed and the respective ratios $\rho$ were calculated for the recorded values of stem densities (Figure 2). It was evident that any randomly defined threshold leads to a ratio $\rho$ above 1.0 and therefore to a disproportionately higher egg density in high-density areas on all sites investigated.

Table 5 Distribution of egg clutches in areas of high stem density at the three study sites.

\begin{tabular}{|c|c|c|c|c|c|c|c|c|c|}
\hline Site & Threshold & $\begin{array}{l}\mathrm{n} \\
\text { control } \\
\text { plots }\end{array}$ & $\begin{array}{l}\mathrm{n} \\
\text { oviposition } \\
\text { plots }\end{array}$ & $\begin{array}{l}\mathrm{n} \text { high-density } \\
\text { control plots }\end{array}$ & $\begin{array}{l}\mathrm{n} \text { high-density } \\
\text { oviposition } \\
\text { plots }\end{array}$ & $\begin{array}{l}\text { Proportion } \\
\text { high-density } \\
\text { control plots }\end{array}$ & $\begin{array}{l}\text { Proportion } \\
\text { high-density } \\
\text { oviposition plots }\end{array}$ & $\begin{array}{l}\text { Ratio } \\
\rho\end{array}$ & $\mathrm{P}$ \\
\hline Lichtlein & $\geq 10$ & 51 & 61 & 18 & 35 & 0.35 & 0.57 & 1.63 & 0.023 \\
\hline Sechsthal & $\geq 7$ & 33 & 32 & 16 & 23 & 0.48 & 0.72 & 1.48 & 0.077 \\
\hline Schafhof & $\geq 7$ & 50 & 60 & 21 & 52 & 0.42 & 0.87 & 2.06 & $<0.001$ \\
\hline
\end{tabular}

Shown are calculated values for the proportion of oviposition plots relative to the proportion of control plots located in areas of high stem density (ratio $\rho$ ) for site-specific thresholds of high stem density. Threshold $=$ mean number of stems in control plots. P-values are given for the Fisher exact test analysing whether the calculated probability ratios $\rho$ differ significantly from a random distribution $(\rho=1)$. 
Figure 2 Distribution of egg clutches in areas of high stem density at the three study sites. Shown are calculated values for the proportion of oviposition plots relative to the proportion of control plots located in areas of high stem density (ratio $\rho$ ) for different arbitrarily presumed thresholds of high stem density. The value of 1.0 would indicate that the increase in egg clutches per area is directly proportional to the increase in stem number (null hypothesis). The grey bar indicates the actual thresholds of stem density derived from the mean number of stems recorded within control plots.

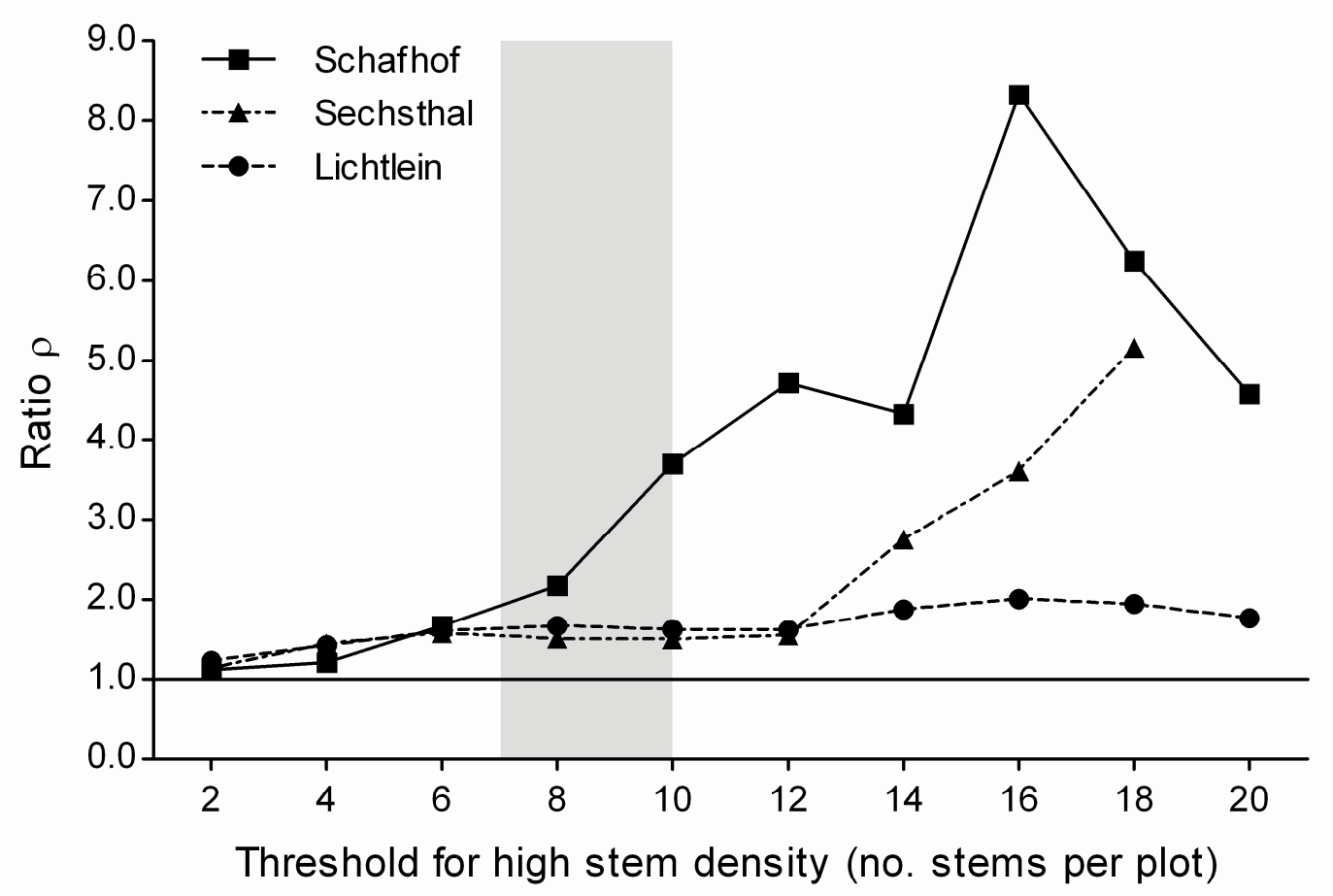

\section{Two-choice bioassays}

In the stem density bioassay arena, leaf beetle females laid more egg clutches in the field with the higher number of stems (field B) (Table 6, Figures 1A, 3A). The observed ratio of egg deposition in fields $\mathrm{A}$ and $\mathrm{B}$ was 13:18. The expected ratio of $1: 2$ in case of an effect of the number of stems alone on oviposition did not differ significantly from the observed ratio $\left(\chi^{2}=0.62\right.$, d.f. $\left.=1, \mathrm{P}=0.430 ; \mathrm{n}=31\right)$. This implies that the absolute number of stems affected oviposition of $G$. tanaceti. For stem density there was a strong trend towards a difference between observed ratio and expected ratio of $1: 4\left(\chi^{2}=3.72\right.$, d.f. $\left.=1, \mathrm{P}=0.054 ; \mathrm{n}=31\right)$. Egg clutches within the arena, therefore, were not deposited directly proportionally to stem density (null-hypothesis), but fewer oviposition events took place on the high density field than expected. Like- wise, it differed significantly from a ratio of $2: 1\left(\chi^{2}=4.17\right.$, d.f. $=1$, $\mathrm{P}=0.041 ; \mathrm{n}=31$ ), thus the size of the area can be excluded as a key factor for egg deposition. In the stem height assay, beetles oviposited significantly more often on tall than on short stems $(25: 11)$ compared with a 1:1 random distribution of egg clutches $\left(\chi^{2}=5.4\right.$, d.f. $=1$, $\mathrm{P}=0.019 ; \mathrm{n}=36$ ) (Figure $3 \mathrm{~B}$ ). On single stems, beetles oviposited not randomly but chose an oviposition site mostly within the upper $20 \%$ of a stem [oviposition height: tall stems $(45 \mathrm{~cm})$ : $38.64 \pm 1.62$; short stems $(15 \mathrm{~cm}): 13.22 \pm 0.34]$. When movement patterns of individual females were analysed, neither walking time $(Z=-1.347, \mathrm{P}=0.178 ; \mathrm{n}=32)$ nor resting time $(\mathrm{Z}=-0.360, \mathrm{P}=0.719 ; \mathrm{n}=32)$ differed significantly between short and tall stems. In the connectivity assay there was a trend towards a higher number of oviposition events on highly connected stems than on unconnected stems (17:10), but the distribution was not significantly different from a 1:1 random distribution $\left(\chi^{2}=1.815\right.$, d.f. $=1, \mathrm{P}=0.178 ; \mathrm{n}=27$ ) (Figure $3 \mathrm{C}$ ). Again, movement patterns of individual females did not differ, neither in walking time 
$(Z=-0.418, P=0.676 ; n=37)$ nor in resting time $(Z=-0.551, P=0.582 ; n=37)$ between highly connected and unconnected stems.

Figure 3 Bioassays testing the number of oviposition events of Galeruca tanaceti according to the different traits of vegetation structure: $(A)$ oviposition at different stemdensities $(\mathrm{P}=0.054$; $\mathrm{n}=31)$, (B) oviposition at different stemheights $(\mathrm{P}=0.019 ; \mathrm{n}=36)$, and $(\mathrm{C})$ oviposition at different stemconnectivities ( $\mathrm{P}=0.178 ; \mathrm{n}=27)$.Numberofactualovipositionevents (grey) is compared with number of expected oviposition events due to the nullmodel (white). The $\chi^{2}$ goodness-of-fit test was used to compare expected values with the observed number of egg depositions.
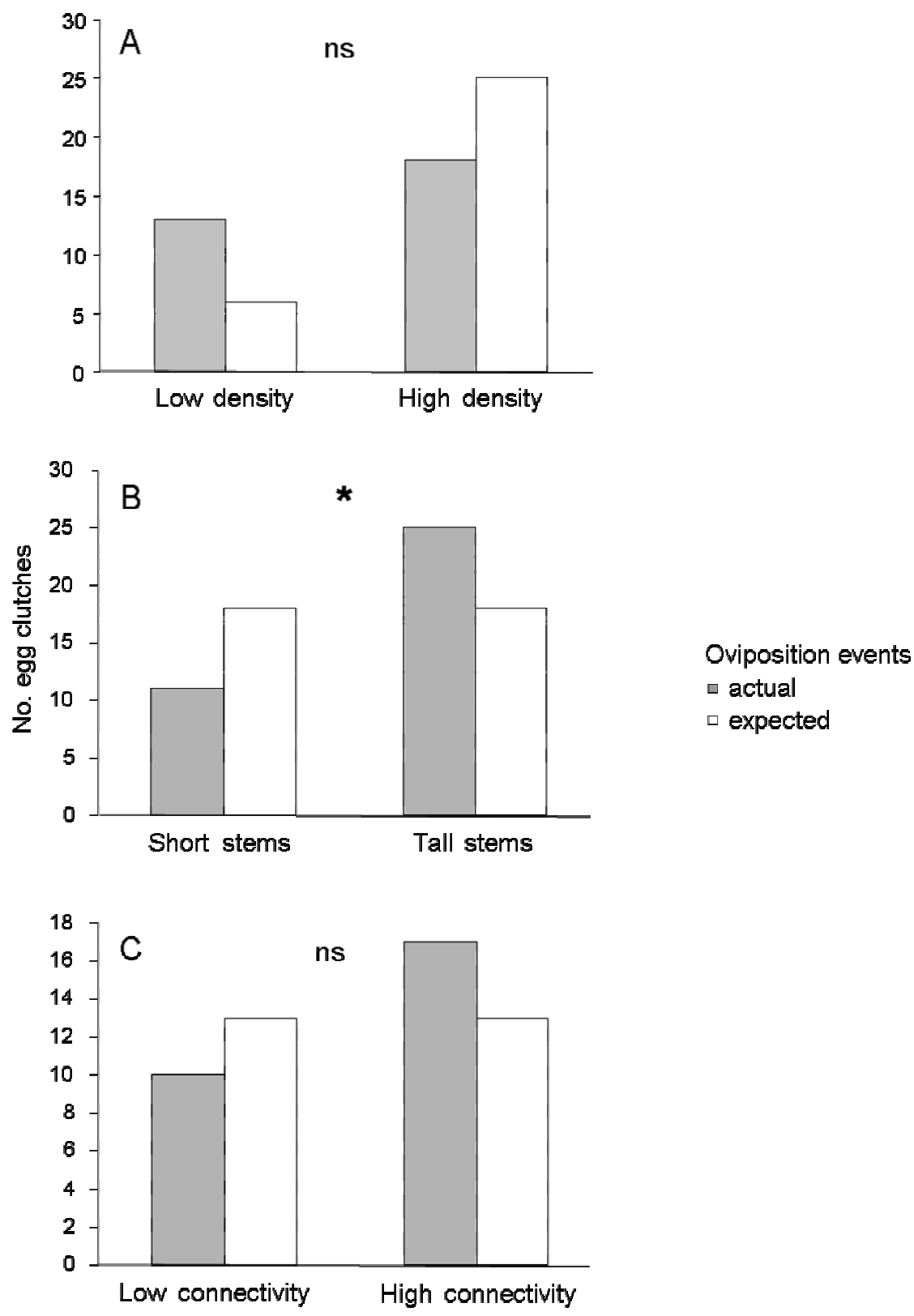
Table 6 Test of the variables stem density, absolute number of stems, and size of the area with stems for oviposition site choice of Galeruca tanaceti in a two-choice bioassay arena. Given are the ratios of the available stem densities (number of stems per unit area), the number of stems, and the areas of the two fields (A and B) offered to the beetles. Expected values were calculated according to these ratios on the basis of the total number of eggs laid during the test. In order to compare expected values with the observed number of egg depositions the $\chi^{2}$ test of goodness-of-fit was used

\begin{tabular}{|c|c|c|c|c|}
\hline & \multirow[b]{2}{*}{ Field } & \multicolumn{3}{|l|}{ Explaining factor } \\
\hline & & Stem density & $\begin{array}{l}\text { Absolute } \\
\text { no. stems }\end{array}$ & Area \\
\hline Expected ratio & $\mathrm{A}: \mathrm{B}$ & $1: 4$ & $1: 2$ & $2: 1$ \\
\hline Expected values with $n=31$ & $\mathrm{~A}: \mathrm{B}$ & $6: 25$ & $10: 21$ & $21: 10$ \\
\hline Observed egg depositions & $\mathrm{A}: \mathrm{B}$ & $13: 18$ & $13: 18$ & $13: 18$ \\
\hline$\chi^{2}$ & & 3.72 & 0.62 & 4.17 \\
\hline D.f. & & 1 & 1 & 1 \\
\hline $\mathrm{P}$ & & 0.054 & 0.430 & 0.041 \\
\hline
\end{tabular}

\section{Discussion}

Our results demonstrated that various traits of the vegetation structure can profoundly affect egg deposition behaviour of $G$. tanaceti. The distribution of $G$. tanaceti egg clutches was strongly influenced by the structural parameters maximum vegetation height and stem density. In the field, oviposition became more likely as vegetation height and stem density increased. These two parameters could be extracted as key factors for oviposition site selection independently for the three grassland sites investigated. Furthermore, the influence of vegetation height was also supported by laboratory experiments. Connectivity of the vegetation had no influence on oviposition site choice of the herbivore either in the field or in arena assays.

Other studies investigating the effect of vegetation density on oviposition preference of herbivores have mostly focused on host plant density, i.e., the quantity of the food resource (Thompson \& Quisenberry, 1995; Shea et al., 2000; Nomakuchi et al., 2001; Stiling \& Moon, 2005). The findings reported were highly variable. They either revealed a positive effect, no effect, or a negative effect of host plant density on the choice of the oviposition site and herbivore abundance (cf. Rhainds \& structure and host plant availability, the various structural traits were correlated with host plant cover English-Loeb, 2003). Studies that investigated the density of the entire vegetation of a natural habitat and its effect on phytophagous insects are rare (Langellotto \& Denno, 2004; Tschanz et al., 2005). In contrast to Tschanz et al. (2005), the results presented here revealed a positive relationship between leaf beetle egg deposition and the density of vegetation in the field.

In order to gain a more detailed insight into the mechanism that underlies egg laying behaviour of $G$. tanaceti in vegetations of varying denstities, we tested whether the observed increase in oviposition probability in areas with high stem density was only by chance, i.e., directly proportional to the increase in stem density, or whether the leaf beetle deliberately chose to oviposit in high stem density areas. The field survey revealed that leaf beetle females indeed showed a clear preference for areas with high plant stem density. This was even true independently of any hypothesised threshold of the mean stem number separating high- 
density areas from low-density areas (Figure 3). The percentages of plots with high stem density [35\% (site Lichtlein), 48\% (site Sechsthal), and 42\% (site Schafhof)] among the randomly selected control plots was quite high and highly suitable patches were therefore abundant within sites.

In a two-choice bioassay, the response of ovipositing leaf beetles to two different grass stem densities was examined. In contrast to the field results, the observed numbe of egg depositions in the arena experiment was not disproportionately higher in the high-density area of the arena, i.e., leaf beetle females seemed to not deliberately choose to deposit their egg clutches in high-density areas in the bioassay. Still, the absolute number of stems seemed to be a regulating factor, as the stem encounter rate influenced oviposition site selection of the leaf beetle females within the arenas.

Host plant height has been examined in several studies as a factor potentially determining the choice of oviposition site or number of eggs laid (Hopkins \& Whittaker, 1980; Björkman et al., 1997; Nomakuchi et al., 2001; Agrawal \& Van Zandt, 2003). There are, however, only few investigations on the effect of plant height per se or the surrounding vegetation height on herbivores (Obermaier et al., 2006). In agricultural settings, tall intercrops have been shown to reduce herbivore immigration, density, and egg deposition (Coll \& Bottrell, 1994; Åsman et al., 2001). Vegetation height was the most important factor determining oviposition site choice of the leaf beetle in this study in the field and in the laboratory. Females preferred to oviposit in tall vegetation and on tall stems in the bioassay arena and chose high oviposition sites close to the tips. For the arena assay, a 1:1 ratio as null hypothesis for the distribution of the egg clutches on tall and short stems was used. Alternatively, a 3:1 ratio according to the length of the stems would have also been possible. The 1:1 ratio of egg clutch distribution, however, seemed to be the more valid hypothesis for this assay for two reasons: if stems were encountered randomly by females, each stem should have had the same chance to have an egg clutch deposited on it. Moreover, in standardised observations on the movement behaviour of individual beetles that were performed in the stem arenas, neither total walking time nor total resting time per observation period $(10 \mathrm{~min})$ differed significantly between short and tall stems ( $\mathrm{n}=33$ females tested individually). If, however, the time the beetles spent on short and on tall stems was independent of the height of the stems, a 1:1 ratio seemed to best fit the circumstances.

The measure of connectivity has so far been exclusively used as a trait characterising plant architecture (number of branchings within plants) (Gingras et al., 2002). We extended the definition to a larger spatial scale by regarding the connectivity of whole vegetation patches and surveyed its effect on parasitoid movement in a further study (B Randlkofer, E Obermaier, J Casas \& T Meiners, unpubl.). To the best of our knowledge, there is very little information available on the effect of connectivity of the vegetation on herbivorous insects on larger scales. Marquis et al. (2002) compared the abundance and amount of damage caused by caterpillars on white oaks varying in plant architectural traits. Augmenting the number of touching leaves artificially increased the abundance of caterpillars and the amount of plant damage in a natural secondary oak forest habitat. The proportion of connecting structures with no dead ends or leading in horizontal direction enhanced the mobility of plant bug nymphs (Lygus rugulipennis Poppius) within an artificial plant canopy (Hannunen, 2002). These examples illustrate that a complex vegetation structure does not necessarily impair herbivore movement, but a high degree of connectivity between plant parts may enhance the movement ability. In this study, the degree of connectivity of the vegetation, in contrast to stem density and height, had no effect on oviposition preference of the leaf beetle either in the field or in the laboratory.

Field investigations and laboratory assays were consistent in their results for vegetation height (positive influence on oviposition) as well as connectivity (no influence), they differed, however, for vegetation density. For possible explanations, field data of this study were reanalysed together with data on host plant cover (Randlkofer et al., 2007). We concluded 
that correlations with host plant cover were rather weak overall $(\mathrm{r}<0.2)$, and of the three vegetation parameters investigated only stem density was (Table 4). There was a significant negative correlation between mean vegetation height and host plant cover (A. millefolium and $C$. jacea $)$ in microhabitats when data of all three field sites were combined $(\mathrm{r}=-0.152$, $\mathrm{P}=0.010 ; \mathrm{n}=287$ ). Vegetation density (stem number) correlated positively with host plant cover $(\mathrm{r}=0.168, \mathrm{P}=0.004 ; \mathrm{n}=287)$. Connectivity was investigated in a 2 nd year, but was not correlated with host plant cover on either site (Hoher Landsberg: $\mathrm{r}=-0.015, \mathrm{P}=0.859$; significantly positively correlated with host plant cover in 1 of 2 years investigated. As far as vegetation height was concerned, it was not or negatively correlated with host plant cover and could therefore not be used as explanation for the preference of the beetles for high structures. Actually, it seems that in spite of lower food availability in high vegetation patches, beetles preferred to oviposit there. Concerning stem density, it can, however, not be excluded that the preference of high density patches by the beetles observed in the field may partly have been due also to a higher host plant cover in theses patches.

Reproductive success depends directly on the behaviour that leads to the encounter of suitable hosts (Castelo et al., 2006). To investigate the underlying mechanisms of oviposition site choice in complex vegetation, standardised behavioural observations of female beetles in the bioassay arenas were performed. This was done only in the height and the connectivity assay; behaviour in the density assay, however, was expected to be comparable. There was no significant difference in total walking time on short and tall stems, and on highly connected and unconnected stems of female beetle individuals. Results suggest that beetles climbed stems at first randomly and, at a suitable oviposition site, started to oviposit.

The structure of the vegetation cannot only directly influence herbivore performance but also indirectly via their natural enemies. Most of the studies dealing with structural complexity and its influence on natural enemieselucidate that complex vegetation structure and plant architecture exerted a negative influence on the foraging efficiency of natural enemies (e.g., Cloyd \& Sadof, 2000; Gingras et al., 2002; Tschanz et al., 2005). For the leaf herbivore investigated in this study there are at least two main selection pressures known to cause the preference of dense and tall vegetation. Parasitism by the specialised egg parasitoid O. galerucivorus decreased significantly with increasing oviposition height (Obermaier et al., 2006) and in structurally complex, tall, and dense vegetation (Obermaier et al., 2008). Furthermore, winter mortality of egg clutches decreased with increasing oviposition height (Obermaier et al., 2006). Additionally, in a study on the influence of structural complexity of vegetation on the movement behaviour of $O$. galerucivorus, the same three vegetation traits, density, height, and connectivity, were investigated in separate bioassay arenas, as in this study. The parameters vegetation height and, even more important, connectivity had a significant influence on time the parasitoid spent walking, whereas vegetation density was not found to be important. In high connectivity assays, fewer wasps reached the top of the stems probably because the connection points disorient them and cause them to lose time, reverse their direction, or fly away (B Randlkofer, E Obermaier, J Casas \& T Meiners, unpubl.).

When comparing the results of this study with observations on the egg parasitoid (Obermaier et al., 2006, 2008; B Randlkofer, E Obermaier, J Casas \& T Meiners, unpubl.) vegetation traits influencing the herbivore and the parasitoid were not completely consistent. Vegetation height seemed to be important for both the oviposition pattern of the herbivore and the movement pattern of the parasitoid, whereas vegetation density seemed to matter only for the herbivore in the field. Thus, laying eggs at the tips of long grass stems in dense vegetation seemed to be an adaptive strategy for the herbivore because this type of vegetation structure assured a maximised number of connection points between plant parts, thereby influencing the movement behaviour of the parasitoid negatively. The results of this study underline that single specific traits of the vegetation can promote herbivore egg deposition as revealed in laboratory assays, while in the field within structurally complex vegetation all structural features present act in concert. 


\section{Acknowledgements}

The authors would like to thank Hans-Joachim Poethke and Monika Hilker for hosting the project during the field and the laboratory work and for fruitful discussions, as well as three anonymous reviewers for valuable comments on a previous version of the manuscript. Ina Heidinger assisted with data recording in the field and Dorothee Hahne assisted in the laboratory. B.R. was supported by the NaFöG scholarship programme and the 'Berliner Programm zur Förderung der Chancengleichheit für Frauen in Forschung und Lehre' of the federal state of Berlin. We thank the council of Lower Franconia for permission to work in the nature reserve 'Hohe Wann'.

\section{References}

Agrawal AA \& Van Zandt PA (2003) Ecological play in the coevolutionary theatre: Genetic and environmental determinants of attack by a specialist weevil on milkweed. Journal of Ecology 91: 1049-1059.

Andow DA \& Prokrym DR (1990) Plant structural complexity and host-finding by a parasitoid. Oecologia 82: 162-165.

Åsman K, Ekbom B \& Rämert B (2001) Effect of intercropping on oviposition and emigration behavior of the leek moth (Lepidoptera: Acrolepiidae) and the diamondback moth (Lepidoptera: Plutellidae). Environmental Entomology 30: 288-294.

Bach CE (1993) Movement behavior of Altica subplicata (Coleoptera: Chrysomelidae): effects of plant characteristics on patterns of adult movement. Journal of the Kansas Entomological Society 66: 310-318.

Björkman C, Larsson S \& Bommarco R (1997) Oviposition preferences in pine sawflies: A trade-off between larval growth and defence against natural enemies. Oikos 79: 45-52.

Bonn A \& Schröder B (2001) Habitat models and their transfer for single and multi species groups: a case study of carabids in an alluvial forest. Ecography 24: 483-496.

Casas J \& Djemai I (2002) Canopy architecture and multitrophic interactions. Multitrophic Level Interactions (ed. by T Tscharntke \& BA Hawkins), pp. 174-196. Cambridge University Press, Cambridge, UK.

Castelo MK, Ney-Nifle M, Corley JC \& Bernstein C (2006) Oviposition height increases parasitism success by the robber fly Mallophora ruficauda (Diptera: Asilidae). Behavioral Ecology and Sociobiology 61: 231-243.

Cloyd RA \& Sadof CS (2000) Effects of plant architecture on the attack rate of Leptomastix dactylopii (Hymenoptera: Encyrtidae), a parasitoid of the citrus mealybug (Homoptera: Pseudococcidae). Environmental Entomology 29: 535-541.

Coll M \& Bottrell DG (1994) Effects of nonhost plants on an insect herbivore in diverse habitats. Ecology 75: 723-731.

Dennis RLH (2004) Just how important are structural elements as habitat components? Indication from a declining lycaenid butterfly with priority conservation status. Journal of Insect Conservation 8: 37-45.

Finch S \& Collier RH (2000) Host-plant selection by insects - a theory based on 'appropriate/inappropriate landings' by pest insects of cruciferous plants. Entomologia Experimentalis et Applicata 96: 91-102.

Gingras D, Dutilleul P \& Boivin G (2002)Modeling the impact of plant structure on host-finding behavior of parasitoids. Oecologia 130: 396-402.

Goodwin BJ \& Fahrig L (2002) Effect of landscape structure on the movement behaviour of a specialized goldenrod beetle, Trirhabda borealis. Canadian Journal of Zoology 80: 24-35.

Hanley JA \& McNeil BJ (1982) The meaning and use of the area under a receiver operating characteristic (ROC) curve. Radiology 143: 29-36.

Hanley JA \& McNeil BJ (1983) A method of comparing the areas under receiver operating characteristic curves derived from the same cases. Radiology 148: 839-843.

Hannunen S (2002) Vegetation architecture and redistribution of insects moving on the plant surface. Ecological Modelling 155: 149-157. 
Hopkins MJG \&Whittaker JB (1980) Interactions between Apion species (Coleoptera: Curculionidae) and Polygonaceae I. Apion curtirostre Germ. and Rumex acetosa L. Ecological Entomology 5: 227-239.

HosmerDW\& Lemeshow SL (1989) Applied Logistic Regression. Wiley,New York, NY, USA.

Jopp F (2006) The impact of local spatial resistance on the movement behavior of Tenebrio molitor $\mathrm{L}$. Central European Journal of Biology 1: 412-429.

Langellotto GA \& Denno RF (2004) Responses of invertebrate natural enemies to complex-structured habitats: a meta-analytical synthesis.Oecologia 139: 1-10.

Lühmann M (1939) Beiträge zur Biologie der Chrysomeliden. 4. Beobachtungen an Galeruca tanaceti Lin. Entomologische Blätter 35: 91-95.

Marquis RJ, Lill JT \& Piccinni A (2002) Effect of plant architecture on colonization and damage by leaftying caterpillars of Quercus alba. Oikos 99: 531-537.

McCoy ED \& Bell SS (1991) Habitat structure: the evolution and diversification of a complex topic. Habitat Structure: The Physical Arrangement of Objects in Space (ed. by SS Bell, ED McCoy \& HR Mushinsky), pp. 3-27. Chapman \& Hall, London, UK.

Meiners T \& Obermaier E (2004) Hide and seek on two spatial scales - vegetation structure effects herbivore oviposition and egg parasitism. Basic and Applied Ecology 5: 87-94.

Meiners T, Randlkofer B \& Obermaier E (2006) Oviposition at low temperatures - late season negatively affects the leaf beetle Galeruca tanaceti (Coleoptera: Galerucinae) but not ist specialised egg parasitoid Oomyzus galerucivorus (Hymenoptera: Eulophidae). European Journal of Entomology 103: 765-770.

Nagelkerke NJD (1991) A note on a general definition of the coefficient of determination. Biometrika 78: 691-692.

Nomakuchi S,Masumoto T, Sawada K, Sunahara T, Itakura N \& Suzuki N (2001) Possible agedependent variation in eggloaded host selectivity of the Pierid butterfly, Anthocharis scolymnus (Lepidoptera: Pieridae): a field observation. Journal of Insect Behavior 14: 451458.

Obermaier E \& Zwölfer H (1999) Plant quality or quantity? Host exploitation strategies in three Chrysomelidae species associated with Asteraceae host plants. Entomologia Experimentalis et Applicata 92: 165-177.

Obermaier E,Heisswolf A, Randlkofer B \& Meiners T (2006) Enemies in low places - insects avoid winter mortality and egg parasitism by modulating oviposition height. Bulletin of Entomological Research 96: 337-343.

Obermaier E, Heisswolf A, Poethke HJ, Randlkofer B \& Meiners T (2008) Plant architecture and vegetation structure: two ways for insect herbivores to escape parasitism. European Journal of Entomology 105: 233-240.

Perrin RM \& Phillips ML (1978) Some effects of mixed cropping on the population dynamics of insect pests. Entomologia Experimentalis et Applicata 24: 585-593.

Prevett PF (1953) Notes on the feeding habits and life-history of Galeruca tanaceti L. (Col., Chrysomelidae). Entomologist's Monthly Magazine 89: 292-293.

Price PW, Bouton CE, Gross P, McPheron BA, Thompson JN \& Weis AE (1980) Interactions among three trophic levels: influence of plants on interactions between insect herbivores and natural enemies. Annual Review of Ecology and Systematics 11: 41-65.

Raghu S, Drew RAI \& Clarke AR (2004) Influence of host plant structure and microclimate on the abundance and behavior of a tephritid fly. Journal of Insect Behavior 17: 179-190.

Randlkofer B, Obermaier E \& Meiners T (2007) Mother's choice of the oviposition site: balancing risk of egg parasitism and need of food supply for the progeny with an infochemical shelter? Chemoecology 17: 177-186.

Rhainds M \& English-Loeb G (2003) Testing the resource concentration hypothesis with tarnished plant bug on strawberry: density of hosts and patch size influence the interaction between abundance of nymphs and incidence of damage. Ecological Entomology 28: 348-358.

Riihimäki J, Vehviläinen H, Kaitaniemi P \& Koricheva J (2006) Host tree architecture mediates the effect of predators on herbivore survival. Ecological Entomology 31: 227-235.

Roditakis E \& Roditakis NE (2006) First record of Galeruca tanaceti in organic Origanum vulgare in Crete. Phytoparasitica 34: 486-487.

Scherf H (1966) Beobachtungen an Ei und Gelege von Galeruca tanaceti L. (Coleoptera, Chrysomelidae). Biologisches Zentralblatt 1: 7-17. 
Shaw MR (2006) Habitat considerations for parasitic wasps (Hymenoptera). Journal of Insect Conservation 10: 117-127.

Shea K, Smyth M, Sheppard A,Morton R \& Chalimbaud J (2000) Effect of patch size and plant density of Paterson's curse (Echium plantagineum) on the oviposition of a specialist weevil, Mogulones larvatus.Oecologia 124: 615-621.

Sholes ODV (2008) Effects of associational resistance and host density on woodland insect herbivores. Journal of Animal Ecology 77: 16-23.

Siew YC (1966) Some physiological aspects of adult reproductive diapause in Galeruca tanaceti (L.) (Coleoptera: Chrysomelidae). Transactions of the Royal Entomological Society London 118: 359-374.

Stiling P \& Moon DC (2005) Quality or quantity: the direct and indirect effects of host plants on herbivores and their natural enemies. Oecologia 142: 413-420.

Thompson RA \& Quisenberry SS (1995) Rice plant-density effect on rice water weevil (Coleoptera: Curculionidae) infestation. Environmental Entomology 24: 19-23.

Tschanz B, Schmid E \& Bacher S (2005) Host plant exposure determines larval vulnerability - do prey females know? Functional Ecology 19: 391-395.

Veldtman R, McGeoch MA \& Scholtz CH (2007) Fine-scale abundance and distribution of wild silk moth pupae. Bulletin of Entomological Research 97: 15-27.

Zweig MH \& Campbell G (1993) Receiver-operating characteristic (ROC) plots - a fundamental evaluation tool in clinical medicine. Clinical Chemistry 39: 561-577. 